\title{
The impact of sitting time and physical activity on major depressive disorder in South Korean adults: a cross-sectional study
}

\author{
Jin Young Nam ${ }^{1,2}$, Juyeong Kim ${ }^{1,2}$, Kyoung Hee Cho ${ }^{2}$, Jaewoo Choi ${ }^{3}$, Jaeyong Shin ${ }^{2,4}$ and Eun-Cheol Park $2,4^{*}$
}

\begin{abstract}
Background: Previous studies have examined associations between sitting time and negative health outcomes and mental health. However, the relationship between overall sitting time and major depressive disorder (MDD) in South Korea has not been studied. This study examined the association between MDD and overall sitting time and physical activity in South Koreans.

Methods: Data from the sixth Korean National Health and Nutrition Examination Survey (KNHANES), a cross-sectional, nationally representative survey, were analyzed. Total participants were 4145 in 2014. MDD was assessed using the Patient Health Questionnaire (PHQ-9). Participants' data regarding self-reported sitting time and physical activity were analyzed via multiple logistic regression.

Results: Results showed that people who sat for $8-10 \mathrm{~h}(\mathrm{OR}: 1.56,95 \% \mathrm{Cl}: 1.15-2.11)$ or more than $10 \mathrm{~h}$ (OR: 1.71, 95\% Cl: 1.23-2.39) had increased risk of MDD compared to those who sat for less than $5 \mathrm{~h}$ a day. Subgroup analysis showed that the strongest effect of reported sitting time on risk of MDD was found in men with lower levels of physical activity who sat for 8 to $10 \mathrm{~h}$ (OR: 3.04, 95\% Cl: 1.15-8.01) or more than $10 \mathrm{~h}$ (OR: 3.43, 95\% Cl: 1.26-9.35). Level of physical activity was not an independent predictor for MDD.

Conclusions: Sitting for long periods was associated with greater risk of MDD in South Korean adults. Reducing sitting time in people with MDD could help to prevent associated physical health problems and may improve mental health.
\end{abstract}

Keywords: Major depressive disorder, PHQ-9, Physical activity, Sedentary behavior, Sitting time

\section{Background}

Major depressive disorder (MDD) is an important public health issue, with a lifetime prevalence of approximately 11-15\% worldwide [1]. The World Health Organization (WHO) recently stated that MDD was expected to be the second leading cause of disability and fourth leading contributor to the global burden of disease by 2020 [2]. Moreover, MDD not only contributes to the overall global burden of disease but also leads to suicide in some individuals [3]. In fact, South Korea has the highest suicide rate of those reported by Organization for Economic

\footnotetext{
* Correspondence: ecpark@yuhs.ac

${ }^{2}$ Institute of Health Services Research, Yonsei University, Seoul, Republic of Korea

${ }^{4}$ Department of Preventive Medicine, Yonsei University College of Medicine, 50 Yonsei-ro, Seodaemun-gu, 120-752 Seoul, Republic of Korea

Full list of author information is available at the end of the article
}

Co-operation and Development (OECD) countries. The lifetime prevalence of MDD based on DSM-IV was 7.5\% [4] while other research presented the prevalence of MDD based on CESD-11 as 11 and $10.6 \%$, respectively [5, 6], which were not high rates of MDD compared to those of OECD countries, and the lowest level of antidepressant consumption in Korea has been recorded as the lowest of these countries [7]. The relatively fewer expressions for depressed mood in Asian populations may have resulted in under-reporting of depressive disorders [8]. These rates could be considered a proxy indicator of the population's mental health. [9]. To reduce this burden, it is necessary to identify crucial risk factors associated with MDD prevention and management.

Physical activity (PA) is known to be associated with a decreased risk of mortality and morbidity resulting from 
chronic conditions such as cardiovascular disease (CVD) $[10,11]$, type 2 diabetes [12-14], obesity [15, 16], and cancer [17-19]. Moreover, recent research suggests that PA is related to mental health outcomes [20, 21]. Several recent studies have identified sedentary behavior (SB) as another lifestyle factor associated with poor cardiovascular [22-24] and metabolic health outcomes [25, 26] and reduced life expectancy [27, 28]. Recently, numerous studies have reported on the relationship between sitting time, PA, and MDD [29], as well as on the effects of interaction between sedentary time and PA which may affect mental well-being and productivity [30], or a specifically, divided PA (domain of PA or Social context of PA) and/or SB (time spent on sitting while watching TV or using computer, sitting for travel or overall sitting time, or sitting around throughout the week) [21, 31] were related to mental health outcomes; however, such effects are still less well-known.

Numerous studies have reported relationships between SB and mental health in older adults [32, 33], disadvantaged women [21], middle-aged women [29], employed adults [31], and patients with schizophrenia [26]; however, the definition of SB included only leisure-time, such as that spent watching TV and/or using a computer or the Internet $[34,35]$. Moreover, no studies have examined associations between MDD and PA and overall sitting time including that involved in work, leisure, home-based activities, and transportation. Therefore, the aims of this study were to examine the relationship between sitting-time and MDD and estimate the effects of sitting-time and PA on MDD in a representative South Korean population.

\section{Methods}

\section{Participants, design and setting of study}

The study used data collected during the second year (2014) of the sixth Korean National Health and Nutrition Examination Survey (KNHANES), which was conducted by the Korea Centers for Disease Control and Prevention (KCDC) in South Korea. The KNHANES is a cross-sectional, nationally representative survey that has been conducted regularly since 1998 , to examine the general health and nutritional status of Korean citizens. The initial sample included 9701 individuals aged $>1$ year, who were invited to participate in the second year (2014) of the sixth KNHANES. Of these, 7550 completed the survey (response rate: $77.8 \%$ ).

The study included adults aged $\geq 20$ years who had participated in the 2014 survey. Data for individuals who were younger than 19 years of age $(n=1653)$ or had been diagnosed with cancer $(n=114)$ and those for whom no information regarding depressive symptoms, sitting times, or covariates was provided $(n=710)$ were excluded from the study. The total number of eligible participants was 4145 (1664 men, 2481 women).

\section{Measures}

MDD: Patient health questionnaire (PHQ-9)

MDD was assessed using the Patient Health Questionnaire (PHQ-9), which incorporated the 9 criteria upon which a diagnosis of depressive disorder is based in the Diagnostic and Statistical Manual of Mental Disorders, Fourth Edition [36]. Participants were asked to indicate how often each depressive symptom had occurred during the preceding 2 weeks by choosing one of the following options 0 (not at all), 1 (several days), 2 (more than half of the days), and 3 (nearly every day) [36]. Total possible scores range from 0 to 27 , and cut-off points of $5,10,15$, and 20 are usually used as thresholds for mild, moderate, moderately severe, and severe depression, respectively, with a score of 10 recommended as the cutoff point for MDD [36]. However, a previous systematic review of 18 validation studies reported that PHQ-9 cutoff scores between 8 and 11 had acceptable diagnostic characteristics for the detection of MDD [37]. Therefore, a score of 8 was used as the cut-off point for MDD in the current study.

\section{Overall daily sitting time: International physical activity questionnaire (IPAQ)}

Overall daily sitting time was estimated using the longversion of the IPAQ [38, 39] and assessed via the following question: How many hours do you typically spend sitting or lying down while engaged in activities such as working at a desk or computer, visiting friends, driving, reading, writing, watching $T V$, playing games, using the Internet, or listening to music on a usual day? Responses were divided into 4 categories using quartiles: $<5 \mathrm{~h} / \mathrm{d}$, 5-7 h/d, 8-10 h/d, and $>10 \mathrm{~h} / \mathrm{d}$.

\section{Physical activity (PA): International physical activity questionnaire (IPAQ)}

PA was assessed using the Korean version of the longformat IPAQ [39] and estimated using aerobic activity recommended by the Centers for Disease Control and Prevention and the American College of Sports Medicine [40]. Responses were divided into 2 categories; participants who engaged in at least $150 \mathrm{~min}$ of moderate-intensity PA per week, at least $75 \mathrm{~min}$ of vigorous-intensity aerobic activity per week, or a combination of moderate- and vigorous-intensity PA (e.g., 1 min of vigorous-intensity PA and 2 min of moderateintensity PA) for at least 75 min per week were classed as engaging in PA, and those who did not were classed as not engaging in PA. 


\section{Covariates}

Age, household income, educational level, occupation, and marital status were included as socioeconomic factors. Health-related factors included obesity, current smoking status, frequency of alcohol use, and number of chronic diseases. Obesity was assessed according to body mass index, which was divided into four groups: underweight $\left(<18.5 \mathrm{~kg} / \mathrm{m}^{2}\right)$, moderate $\left(18.5-24.9 \mathrm{~kg} / \mathrm{m}^{2}\right)$, overweight $\left(25.0-29.9 \mathrm{~kg} / \mathrm{m}^{2}\right)$, and obese $\left(\geq 30 \mathrm{~kg} / \mathrm{m}^{2}\right)$. Current smoking status was a dichotomous variable, as follows: current smokers or those who had smoked more than 100 cigarettes throughout their lives, and those who had never smoked or had previously smoked less than 100 cigarettes throughout their lives. Frequency of alcohol use was calculated according to the average frequency (more than once per month or never) with which alcohol was consumed during the preceding year. Number of chronic diseases was classified into 3 categories according to the number of diseases, including high blood pressure, dyslipidemia, stroke, myocardial infarction, angina, arthritis, rheumatoid arthritis, chronic renal failure, asthma, thyroid disease, and hepatitis $B$, reported $(0,1$, or $\geq 2)$.

\section{Statistical analysis}

General characteristics were evaluated using chi-square tests. Multiple logistic regression models were created to determine whether sitting time was related to depressive symptoms. In addition, Cochran-Armitage trend test was used to investigate whether there was a linear trend in the relationship between sitting time and MDD. In addition, subgroup analysis was performed according to PA, occupation, and sitting time, using multiple logistic regression. All statistical analyses were performed using SAS 9.4 (SAS Institute, Inc., Cary, NC).

\section{Results}

Table 1 shows the participants' general characteristics. The 4145 participants included 1664 men and 2481 women; of these, 112 (6.7\%) men and 312 (12.6\%) women reported MDD. Sitting time of $\geq 8 \mathrm{~h} / \mathrm{d}$ was reported by $45.6 \%$ of participants. Specifically, men tended to sit excessively more than women. The proportion of men $(20.01 \%)$ who sat for $>10 \mathrm{~h} / \mathrm{d}$ was higher compared to women (16.36\%; Additional file 1: Table S1).

Table 2 presents the estimated odds ratios (ORs) from the multiple logistic regression analysis. Risk of MDD in women was twice that observed in men (OR: 2.00, 95\% CI: 1.49-2.68). Regarding sitting time, risk of MDD in men who sat for $>10 \mathrm{~h} / \mathrm{d}$ was greater relative to those who sat for $<5$ h/d (OR: 2.04, 95\% CI: 1.12-373). Similarly, risk of MDD in women who sat for $\geq 8 \mathrm{~h} / \mathrm{d}$ was greater relative to that of those who sat for $<5 \mathrm{~h} / \mathrm{d}$ (810 h/d: OR: $1.59,95 \%$ CI: $1.12-2.27$; >10 h/d: OR: 1.64 ,
95\% CI: 1.09-2.45). There was a significant association between linear trends of sitting time and MDD $(P=0.0001)$. Both men and women who sat for longer periods were significantly more likely to report higher MDD compared to those who sat for $<5 \mathrm{~h} / \mathrm{d}(P=0.0053$ and $P=0.0040$, respectively). Low level of physical activity was not an independent risk factor for MDD in men or women.

Figure 1 depicts the subgroup analysis in which multiple logistic regression was performed to assess the relationship between sitting time and MDD according to PA. Results showed that men who sat for $\geq 8 \mathrm{~h} / \mathrm{d}$ were at significantly high risk of MDD compared to those who sat for $<5 \mathrm{~h} / \mathrm{d}(8-10 \mathrm{~h} / \mathrm{d}$ : OR: 3.04, 95\% CI: $1.15-8.01$; $>10$ h/d: OR: $3.43,95 \%$ CI: 1.26-9.35). Women who sat for $>10 \mathrm{~h} / \mathrm{d}$ were at greater risk of MDD compared to those who sat for $<5 \mathrm{~h} / \mathrm{d}$ (OR: 2.27, 95\% CI: 1.23-4.21) (Additional file 1: Table S2).

\section{Discussion}

This study is the first to consider evidence for the effect of overall sitting time on risk of MDD in Korea. Using cross-sectional design, our study found that sitting time was positively associated with MDD. Sitting for long periods $(>10 \mathrm{~h} / \mathrm{d})$ was significantly related to higher risk of MDD in both men and women. Sitting for 8-10 h/d was associated with risk of MDD in both sexes; however, the association was statistically significant only in women. In addition, PA was inversely related to MDD risk, although this association was nonsignificant.

The results are consistent with those of previous studies indicating that longer periods of sitting are related to poor mental health $[21,29,32,33,41]$ and PA was negatively associated with risk of depression [20, 21]. However, these studies did not examine sex differences in health outcomes related to SB; one study involved both men and women, but did not examine potential interactions according to sex [33], while others involved only women or assessed the relationship between leisure-related sitting time, such that spent watching TV or using a computer, and depressive symptoms [21,35]. Moreover, a sex difference has previously been observed in mental health outcomes related to sitting time, with findings partially similar to the current results. In the current study, sitting for $>7 \mathrm{~h} / \mathrm{d}$ was associated with greater MDD risk in women relative to that observed in men [31]; however, MDD risk in men who sat for $>10 \mathrm{~h} /$ $\mathrm{d}$ was twice that of men who sat for $<5 \mathrm{~h} / \mathrm{d}$ and higher relative to that of women.

The findings of the current study indicated that there was no interaction between sitting time, PA, and MDD risk; this may have occurred because of the small sample size. However, subgroup analysis was performed because $\mathrm{PA}$ is an important factor in the attenuation of 
Table 1 Participants' general characteristics

\begin{tabular}{|c|c|c|c|c|c|c|c|}
\hline & \multicolumn{7}{|c|}{ Depression } \\
\hline & \multicolumn{2}{|c|}{ Total } & \multicolumn{2}{|c|}{ Yes } & \multicolumn{2}{|c|}{ No } & \multirow[b]{2}{*}{$p$-value } \\
\hline & $\mathrm{N}$ & $(\%)$ & $\mathrm{N}$ & $(\%)$ & N & $(\%)$ & \\
\hline \multicolumn{8}{|l|}{ Sitting time (hours) } \\
\hline$<5$ & 1059 & $(25.55)$ & 86 & $(8.12)$ & 973 & (91.88) & \multirow[t]{4}{*}{0.0012} \\
\hline $5-7$ & 1195 & $(28.83)$ & 107 & $(8.95)$ & 1088 & $(91.05)$ & \\
\hline $8-10$ & 1152 & $(27.79)$ & 136 & $(11.81)$ & 1016 & (88.19) & \\
\hline$>10$ & 739 & $(17.83)$ & 95 & $(12.86)$ & 644 & $(87.14)$ & \\
\hline \multicolumn{8}{|l|}{ Sex } \\
\hline Men & 1664 & $(40.14)$ & 112 & $(6.73)$ & 1552 & $(93.27)$ & \multirow[t]{2}{*}{$<.0001$} \\
\hline Women & 2481 & $(59.86)$ & 312 & $(12.58)$ & 2169 & $(87.42)$ & \\
\hline \multicolumn{8}{|l|}{ Age (year) } \\
\hline $20-29$ & 422 & $(10.18)$ & 53 & $(12.56)$ & 369 & $(87.44)$ & \multirow[t]{6}{*}{0.0056} \\
\hline $30-39$ & 753 & $(18.17)$ & 69 & $(9.16)$ & 684 & $(90.84)$ & \\
\hline $40-49$ & 728 & $(17.56)$ & 56 & $(7.69)$ & 672 & $(92.31)$ & \\
\hline $50-59$ & 806 & $(19.45)$ & 77 & $(9.55)$ & 729 & $(90.45)$ & \\
\hline $60-69$ & 758 & $(18.29)$ & 78 & $(10.29)$ & 680 & $(89.71)$ & \\
\hline $70+$ & 678 & $(16.36)$ & 91 & $(13.42)$ & 587 & $(86.58)$ & \\
\hline \multicolumn{8}{|l|}{ Household income level } \\
\hline Low & 759 & $(18.31)$ & 157 & $(20.69)$ & 602 & $(79.31)$ & \multirow[t]{4}{*}{$<.0001$} \\
\hline Lower middle & 1030 & $(24.85)$ & 105 & $(10.19)$ & 925 & $(89.81)$ & \\
\hline Upper middle & 1214 & $(29.29)$ & 88 & $(7.25)$ & 1126 & $(92.75)$ & \\
\hline High & 1142 & $(27.55)$ & 74 & $(6.48)$ & 1068 & $(93.52)$ & \\
\hline \multicolumn{8}{|l|}{ Educational levels } \\
\hline Middle school or below & 1439 & $(34.72)$ & 196 & $(13.62)$ & 1243 & (86.38) & \multirow[t]{3}{*}{$<.0001$} \\
\hline High school & 1332 & $(32.14)$ & 128 & $(9.61)$ & 1204 & $(90.39)$ & \\
\hline Above college & 1374 & (33.15) & 100 & $(7.28)$ & 1274 & $(92.72)$ & \\
\hline \multicolumn{8}{|l|}{ Occupation } \\
\hline White collar & 927 & $(22.36)$ & 50 & $(5.39)$ & 877 & $(94.61)$ & \multirow[t]{4}{*}{$<.0001$} \\
\hline Pink collar & 500 & $(12.06)$ & 53 & $(10.60)$ & 447 & $(89.40)$ & \\
\hline Blue collar & 989 & $(23.86)$ & 76 & $(7.68)$ & 913 & $(92.32)$ & \\
\hline Unemployed, housewife or students & 1729 & $(41.71)$ & 245 & $(14.17)$ & 1484 & $(85.83)$ & \\
\hline \multicolumn{8}{|l|}{ Marital status } \\
\hline Single & 564 & $(13.61)$ & 66 & $(11.70)$ & 498 & $(88.30)$ & \multirow[t]{3}{*}{$<.0001$} \\
\hline Married & 3069 & $(74.04)$ & 259 & $(8.44)$ & 2810 & $(91.56)$ & \\
\hline Separated & 512 & $(12.35)$ & 99 & $(19.34)$ & 413 & $(80.66)$ & \\
\hline \multicolumn{8}{|l|}{ Physical activity } \\
\hline No & 1968 & $(47.48)$ & 228 & $(11.59)$ & 1740 & $(88.41)$ & \multirow[t]{2}{*}{$<.0001$} \\
\hline Yes & 2177 & $(52.52)$ & 196 & $(9.00)$ & 1981 & $(91.00)$ & \\
\hline \multicolumn{8}{|l|}{ Obesity (BMI, kg/m²) } \\
\hline Low-weight (< 18.5) & 171 & $(4.13)$ & 33 & $(19.30)$ & 138 & $(80.70)$ & \multirow[t]{4}{*}{$<.0001$} \\
\hline Normal (18.5-24.9) & 2652 & $(63.98)$ & 258 & $(9.73)$ & 2394 & $(90.27)$ & \\
\hline Overweight (25.0-29.9) & 1149 & $(27.72)$ & 107 & $(9.31)$ & 1042 & $(90.69)$ & \\
\hline Obesity $(\geq 30.0)$ & 173 & $(4.17)$ & 26 & (15.03) & 147 & $(84.97)$ & \\
\hline
\end{tabular}


Table 1 Participants' general characteristics (Continued)

\begin{tabular}{|c|c|c|c|c|c|c|c|}
\hline \multicolumn{8}{|c|}{ Current Smoking status } \\
\hline No & 3408 & $(82.22)$ & 340 & (9.98) & 3068 & $(90.02)$ & \multirow[t]{2}{*}{$<.0001$} \\
\hline Yes & 737 & $(17.78)$ & 84 & $(11.40)$ & 653 & $(88.60)$ & \\
\hline \multicolumn{8}{|c|}{ Alcohol use } \\
\hline No & 1986 & $(47.91)$ & 226 & $(11.38)$ & 1760 & $(88.62)$ & \multirow[t]{2}{*}{$<.0001$} \\
\hline Yes & 2159 & $(52.09)$ & 198 & $(9.17)$ & 1961 & $(90.83)$ & \\
\hline \multicolumn{8}{|c|}{ Number of chronic diseases ${ }^{a}$} \\
\hline 0 & 2239 & $(54.02)$ & 196 & $(8.75)$ & 2043 & $(91.25)$ & \multirow[t]{3}{*}{$<.0001$} \\
\hline 1 & 1133 & $(27.33)$ & 110 & $(9.71)$ & 1023 & $(90.29)$ & \\
\hline$\geq 2$ & 773 & $(18.65)$ & 118 & $(15.27)$ & 655 & $(84.73)$ & \\
\hline Total & 4145 & $(100.00)$ & 424 & $(10.23)$ & 3721 & $(89.77)$ & \\
\hline
\end{tabular}

${ }^{a}$ Number of chronic diseases: Hypertension, dyslipidemia, stroke, myocardial infarction, angina, arthritis, rheumatoid arthritis, asthma, thyroid gland disorder, chronic renal failure, hepatitis B

depression [29]. Interestingly, the results showed a sex difference. MDD risk in men who did not engage in PA and sat for $\geq 8 \mathrm{~h} / \mathrm{d}$ was approximately 3 times higher relative to that of those who did not engage in PA and sat for $<5 \mathrm{~h} / \mathrm{d}$. In women, MDD risk in those who did not engage in PA and sat for $\geq 8 \mathrm{~h} / \mathrm{d}$ was higher relative to that of those who sat for $<5 \mathrm{~h} / \mathrm{d}$, but the associations between MDD and sitting time and PA were nonsignificant. This indicates that men who did not engage in PA and sat for long periods were likely to experience MDD; Interestingly, risk of MDD in women who engaged in PA and sat for $>10 \mathrm{~h} / \mathrm{d}$ was more than twice that of those who sat for $<5 \mathrm{~h} / \mathrm{d}$. This could have occurred because half of the women in the study population, such as housewives who engaged in PA via daily chores, were unemployed, and unemployed people were at greater risk of MDD relative to employed individuals (Table 2); therefore, MDD risk in women who engaged in PA could have differed according to sitting time.

The results of the current study are consistent with those of a previous Spanish study [35] that examined the combined effect of sitting time and PA on depression. The results showed that risk of mental disorders in those with high PA levels and short periods of SB was 25\% lower relative to that of those with low PA levels and long periods of SB. Moreover, Lucas et al. examined the combined effect of PA and time spent watching TV on depression. Their results suggested that both factors contribute to depression risk, because watching TV typically replaces PA [34]. These studies identified SB as an important correlate of decreased MDD risk when PA levels were low but not when they were high, suggesting that PA could affect the relationship between SB and depression. Even though this was a cross-sectional study and did not explain causal relationships, sitting for long periods and failure to engage in PA increased MDD risk, which is consistent with the findings of previous studies.
Some studies have described potential mechanisms underlying the inverse relationships between PA and sitting-time and MDD. One possible explanation for the positive relationship between sitting time and MDD risk is that sitting time might replace PA [20, 34]. A few studies have suggested that the more time adults spend sitting during activities, such as watching TV, the less time they spend engaging in PA [42]. Numerous studies have shown that PA is not only associated with a reduced risk of negative health outcomes [10-17] but also involved physiological mechanisms including changes in endorphins, core body temperature, central serotonergic systems, and brain activation involved in emotional regulation [43-45]. Another possible explanation for the association between sitting for long periods and high risk of depression involves the social withdrawal hypothesis. Psychosocial mechanisms include distraction, enhanced feelings of control and mastery, improved selfesteem and self-efficacy, behavioral activation, and social interaction [46-48]. For instance, as the frequency with which people watch TV or use a computer or the Internet increases, they become further removed from social interaction, which increases their risk of depression [49]. However, this type of activity must be contrasted with computer or Internet use for work or communication $[50,51]$. Nevertheless, physiological or psychological mechanisms could support the relationship between sitting time and MDD risk. South Korea has the highest proportion of households with broadband Internet access (97.2\%) [52] and the highest business use of broadband (98.4\% of businesses with 10 or more employees) [52] of the OECD countries, along with high levels of mobile penetration and daily mobile use for long periods [53]. It is easy to be exposed to the Internet via computers or mobile phones in South Korea, which could affect the relationships between MDD and sitting-time and PA. As a result, people with depression might have 
Table 2 Association between sitting time and major depressive disorder

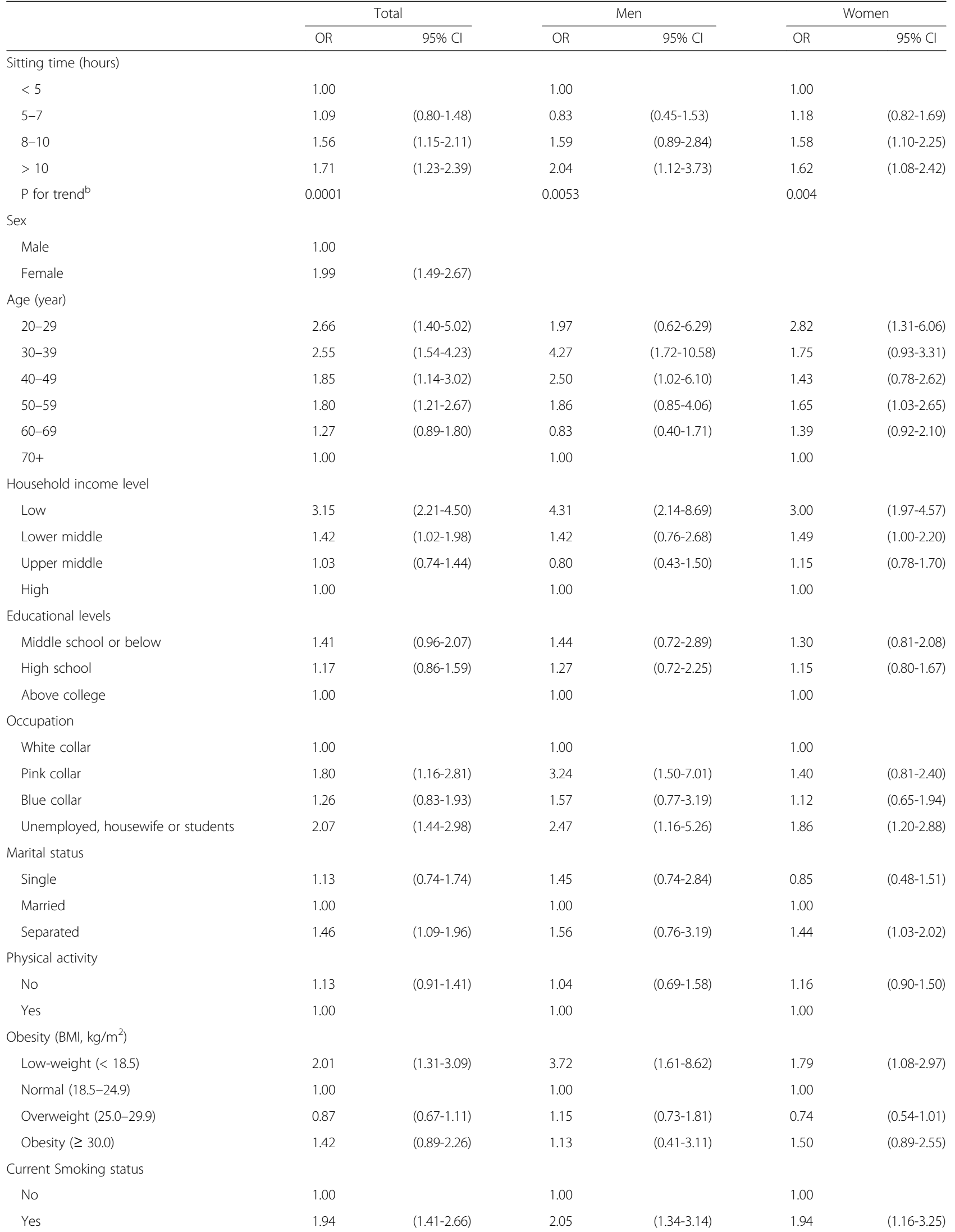


Table 2 Association between sitting time and major depressive disorder (Continued)

\begin{tabular}{|c|c|c|c|c|c|c|}
\hline \multicolumn{7}{|c|}{ Alcohol use } \\
\hline No & 1.00 & & 1.00 & & 1.00 & \\
\hline Yes & 1.09 & $(0.87-1.38)$ & 1.21 & $(0.76-1.95)$ & 1.11 & $(0.85-1.45)$ \\
\hline \multicolumn{7}{|c|}{ Number of chronic diseases ${ }^{a}$} \\
\hline 0 & 1.00 & & 1.00 & & 1.00 & \\
\hline 1 & 1.17 & $(0.88-1.57)$ & 1.11 & $(0.66-1.87)$ & 1.13 & $(0.79-1.61)$ \\
\hline$\geq 2$ & 1.67 & $(1.20-2.33)$ & 1.79 & $(0.95-3.36)$ & 1.55 & $(1.05-2.30)$ \\
\hline
\end{tabular}

aNumber of chronic diseases: Hypertension, dyslipidemia, stroke, myocardial infarction, angina, arthritis, rheumatoid arthritis, asthma, thyroid gland disorder, chronic renal failure, hepatitis B

${ }^{\mathrm{b}}$ Cochran-armitage trend test

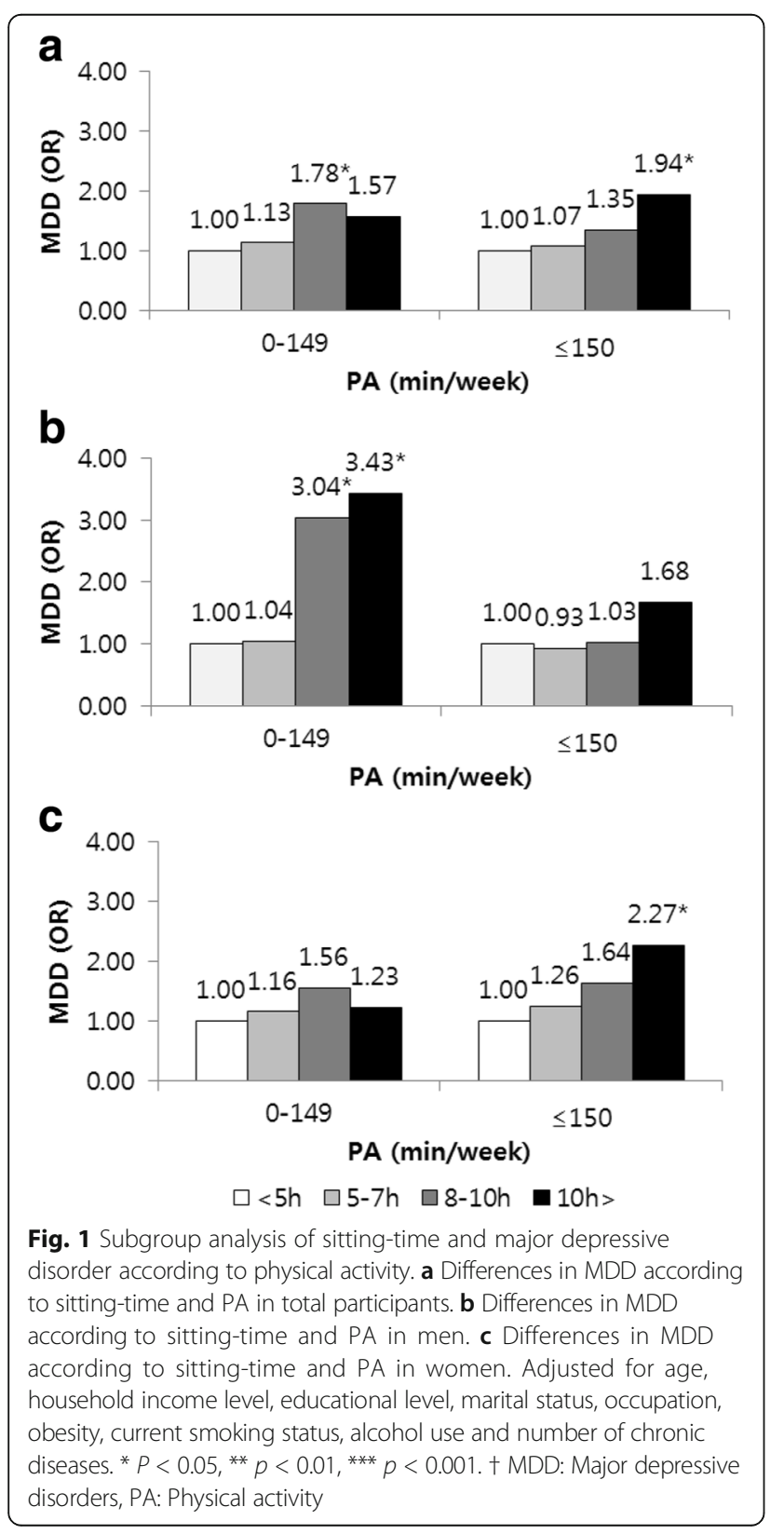

poorer physical health because they were more likely to choose a sedentary lifestyle due to their depressed feeling, fatigue, or evasion of social interaction.

\section{Limitations}

The study was subject to several limitations. First, it was a cross-sectional study and could not explain whether sitting for long periods was the cause or consequence of MDD. Reverse causality is recognized as a potential confounder for the observed association. Second, there could be a cyclical and reciprocal association between sitting-time and MDD because of the nature of mental health conditions, which could lead to overestimation in cross-sectional studies. Third, our research might have validity issues from using self-reported measures of PA and sitting time. In this study, sitting time was assessed by only one question, which asked about a typical day including both work and leisure time. A previous study estimated sitting time separately for weekdays and weekends, as well as for time spent sitting at work or while travelling [30]. In contrast, survey questions in our study did not distinguish between work and non-work days, or work-related or leisure-related sitting time; therefore, we were unable to tell whether specific sitting time affected MDD. However, the aim of the study was to identify the effects of overall sitting time and PA on MDD, and further research should be conducted to overcome this limitation. Fourth, we might have issues with representativeness, as we excluded unavailable missing data which accounted for nearly $20 \%$ of the original survey. Therefore, further research should be considered to make up for the missing data. Fifth, the potential health risks related to valuable evidence could be highly prevalent in contemporary society. In fact, South Korea experienced a serious tragic social event in 2014, which could affect depressed people for a long period and might have contributed to overall reductions or increases in sitting time, affecting MDD.

Nevertheless, the study is unique, because it included a representative sample of the population of an entire country and was the first to examine the relationship 
between sitting time and MDD in South Korea. Moreover, it assessed differences in MDD according to PA and sitting time.

\section{Conclusions}

This study showed that sitting for long periods was associated with greater risk of MDD in South Korean adults. The findings accentuated the importance of reducing overall sitting time and increasing PA and suggested that policymakers should develop strategies involving PA, to decrease sitting time and alleviate the burden of depression in terms of fiscal health premiums and social problems.

\section{Additional file}

Additional file 1: Table S1. Men and women participants' general characteristics. * Number of chronic diseases: Hypertension, dyslipidemia, stroke, myocardial infarction, angina, arthritis, rheumatoid arthritis, asthma, thyroid gland disorder, chronic renal failure, hepatitis B. ${ }^{*}$ Number of chronic diseases: Hypertension, dyslipidemia, stroke, myocardial infarction, angina, arthritis, rheumatoid arthritis, asthma, thyroid gland disorder, chronic renal failure, hepatitis B. Table S2. Subgroup analysis of sitting-time and major depressive disorder according to physical activity. Adjusted for age, household income level, educational level, marital status, occupation, obesity, current smoking status, alcohol use and number of chronic diseases. (DOCX $51 \mathrm{~kb})$

\section{Abbreviations}

CVD: Cardiovascular disease; IPAQ: International physical activity questionnaire; KCDC: Korea centers for disease control and prevention; KNHANES: Korean national health and nutrition examination survey; MDD: Major depressive disorder; OECD: Organization for economic co-operation and development; PA: Physical activity; PHQ-9: Patient Health Questionnaire; SB: Sedentary behavior

\section{Acknowledgements}

We would like to thank the Korean Centers for Disease Control (KCDC), which produced and provided data based on nationwide survey. We would also like to thank the colleagues at the Institute of Health Services Research of Yonsei University, who have provided their advice on intellectual content.

\section{Funding}

All authors have no financial disclosures.

\section{Availability of data and materials}

The KNHANES data are openly available at https://knhanes.cdc.go.kr/knhanes/ index.do by submitting a written statement and data utilization plan.

\begin{abstract}
Authors' contributions
JY Nam conceived the study, in addition to contributing to its design, drafting the manuscript, and wrote the final version of the manuscript. J Kim participated in acquisition of data and drafting the manuscript. $\mathrm{KH}$ Cho and J Choi performed statistical analysis and interpretation of data. J Shin was in charge of revising the manuscript critically for important intellectual content. EC Park conceived, designed and directed this study. All authors read and approved the final manuscript
\end{abstract}

\section{Ethics approval and consent to participate}

The KNHANES survey data are openly published, so ethical approval was not required for this study. This study did not collect inform consent from the participants, because their information was fully anonymized and deidentified prior to analysis.

\section{Competing interest}

The authors declare that they have no competing interest.

\section{Publisher's Note}

Springer Nature remains neutral with regard to jurisdictional claims in published maps and institutional affiliations.

\section{Author details}

${ }^{1}$ Department of Public Health, Graduate School, Yonsei University, Seoul, Republic of Korea. ${ }^{2}$ Institute of Health Services Research, Yonsei University, Seoul, Republic of Korea. ${ }^{3}$ Busan Public Health Policy Institute, Busan, Republic of Korea. ${ }^{4}$ Department of Preventive Medicine, Yonsei University College of Medicine, 50 Yonsei-ro, Seodaemun-gu, 120-752 Seoul, Republic of Korea.

Received: 23 May 2016 Accepted: 23 July 2017

Published online: 28 July 2017

\section{Reference}

1. Bromet E, Andrade LH, Hwang I, Sampson NA, Alonso J, De Girolamo G, De Graaf R, Demyttenaere K, Hu C, Iwata N. Cross-national epidemiology of DSM-IV major depressive episode. BMC Med. 2011:9(90):1-16.

2. Reddy M. Depression: the disorder and the burden. Indian J Psychol Med. 2010:32(1):1-2.

3. World Health Organization. Depression. In: Fact sheet. Geneva: World Health Organization; 2016. http://www.who.int/mediacentre/factsheets/fs369/en/.

4. Cho MJ, Seong SJ, Park JE, Chung I-W, Lee YM, Bae A, Ahn JH, Lee D-W, Bae $\mathrm{JN}$, Cho S-J. Prevalence and correlates of DSM-IV mental disorders in south Korean adults: the Korean epidemiologic catchment area study 2011. Psychiatry Invest. 2015;12(2):164-70

5. Lee J-H, Park SK, Ryoo J-H, Oh C-M, Mansur RB, Alfonsi JE, Cha DS, Lee Y, Mclntyre RS, Jung JY. The association between insulin resistance and depression in the Korean general population. J Affect Disord. 2017;208:553-9.

6. Hong JP, Lee D, Sim Y, Kim YH. Awareness, attitude and impact of perceived depression in the workplace in Korea. J Korean Neuropsychiatr Assoc. 2015;54(2):188-201.

7. Organisation for Economic Co-operation and Development. Health at a Glance 2015: OECD Indicators. Paris: OECD Publishing; 2015. doi:http://dx. doi.org/10.1787/health_glance-2015-en.

8. Jeon HJ, Walker RS, Inamori A, Hong JP, Cho MJ, Baer L, Clain A, Fava M, Mischoulon D. Differences in depressive symptoms between Korean and American outpatients with major depressive disorder. Int Clin Psychopharmacol. 2014;29(3):150-6.

9. Organisation for Economic Co-operation and Development. Making Mental Health Count: The Social and Economic Costs of Neglecting Mental Health Care. Paris: OECD Publishing: 2014. http://dx.doi.org/10.1787/9789264208445-en.

10. Manson JE, Hu FB, Rich-Edwards JW, Colditz GA, Stampfer MJ, Willett WC, Speizer $\mathrm{FE}$, Hennekens $\mathrm{CH}$. A prospective study of walking as compared with vigorous exercise in the prevention of coronary heart disease in women. N Engl J Med. 1999;341(9):650-8.

11. Morris J, Pollard R, Everitt M, Chave S, Semmence A. Vigorous exercise in leisure-time: protection against coronary heart disease. Lancet. 1980; 316(8206):1207-10.

12. Manson JE, Stampfer M, Colditz G, Willett W, Rosner B, Hennekens C, Speizer F, Rimm E, Krolewski A. Physical activity and incidence of non-insulindependent diabetes mellitus in women. Lancet. 1991;338(8770):774-8.

13. Eriksson K-F, Lindgärde F. Prevention of type 2 (non-insulin-dependent) diabetes mellitus by diet and physical exercise the 6-year Malmö feasibility study. Diabetologia. 1991;34(12):891-8.

14. Pan X-R, Li G-W, Hu Y-H, Wang J-X, Yang W-Y, An Z-X, Hu Z-X, Xiao J-Z, Cao $\mathrm{H}-\mathrm{B}$, Liu P-A. Effects of diet and exercise in preventing NIDDM in people with impaired glucose tolerance: the Da Qing IGT and diabetes study. Diabetes Care. 1997;20(4):537-44.

15. Ewing R, Schmid T, Killingsworth R, Zlot A, Raudenbush S. Relationship between urban sprawl and physical activity, obesity, and morbidity. Am J Health Promot. 2003;18(1):47-57.

16. Haapanen N, Miilunpalo S, Pasanen M, Oja P, Vuori I. Association between leisure time physical activity and 10-year body mass change among workingaged men and women. Int J Obes Relat Metab Disord. 1997;21(4):288-96. 
17. Dosemeci M, Hayes RB, Vetter R, Hoover RN, Tucker M, Engin K, Unsal M, Blair A. Occupational physical activity, socioeconomic status, and risks of 15 cancer sites in Turkey. Cancer Causes Control. 1993;4(4):313-21.

18. Holmes MD, Chen WY, Feskanich D, Kroenke CH, Colditz GA. Physical activity and survival after breast cancer diagnosis. JAMA. 2005;293(20):2479-86.

19. Giovannucci E, Ascherio A, Rimm EB, Colditz GA, Stampfer MJ, Willett WC. Physical activity, obesity, and risk for colon cancer and adenoma in men. Ann Intern Med. 1995;122(5):327-34.

20. Teychenne M, Ball K, Salmon J. Physical activity and likelihood of depression in adults: a review. Prev Med. 2008;46(5):397-411.

21. Teychenne M, Ball K, Salmon J. Physical activity, sedentary behavior and depression among disadvantaged women. Health Educ Res. 2010;25(4): 632-44.

22. Hamilton MT, Healy GN, Dunstan DW, Zderic TW, Owen N. Too little exercise and too much sitting: inactivity physiology and the need for new recommendations on sedentary behavior. Curr Cardiovasc Risk Rep. 2008;2(4):292-8.

23. Grøntved A, Hu FB. Television viewing and risk of type 2 diabetes, cardiovascular disease, and all-cause mortality: a meta-analysis. JAMA. 2011;305(23):2448-55

24. Katzmarzyk PT, Church TS, Craig CL, Bouchard C. Sitting time and mortality from all causes, cardiovascular disease, and cancer. Med Sci Sports Exerc. 2009;41(5):998-1005

25. Tremblay MS, Colley RC, Saunders TJ, Healy GN, Owen N. Physiological and health implications of a sedentary lifestyle. Appl Physiol Nutr Metab. 2010;35(6):725-40

26. Vancampfort D, Probst M, Knapen J, Carraro A, De Hert M. Associations between sedentary behaviour and metabolic parameters in patients with schizophrenia. Psychiatry Res. 2012;200(2):73-8.

27. Katzmarzyk PT, Lee I-M. Sedentary behaviour and life expectancy in the USA: a cause-deleted life table analysis. BMJ Open. 2012;2(4):e000828.

28. Teychenne M, Ball K, Salmon J. Sedentary behavior and depression among adults: a review. Int J Behav Med. 2010;17(4):246-54.

29. Van Uffelen JG, van Gellecum YR, Burton NW, Peeters G, Heesch KC, Brown WJ. Sitting-time, physical activity, and depressive symptoms in mid-aged women. Am J Prev Med. 2013:45(3):276-81.

30. Puig-Ribera A, Martínez-Lemos I, Giné-Garriga M, González-Suárez ÁM, BortRoig J, Fortuño J, Muñoz-Ortiz L, McKenna J, Gilson ND. Self-reported sitting time and physical activity: interactive associations with mental well-being and productivity in office employees. BMC Public Health. 2015;15(1):72.

31. Atkin AJ, Adams E, Bull FC, Biddle SJ. Non-occupational sitting and mental well-being in employed adults. Ann Behav Med. 2012;43(2):181-8.

32. Ku P-W, Fox KR, Chen L-J, Chou P. Physical activity, sedentary time and subjective well-being in Taiwanese older adults. Int J Sport Psychol. 2011;42(3):245-62.

33. Hamer M, Stamatakis E, Mishra GD. Television-and screen-based activity and mental well-being in adults. Am J Prev Med. 2010;38(4):375-80.

34. Lucas M, Mekary R, Pan A, Mirzaei F, O'Reilly ÉJ, Willett WC, Koenen K, Okereke OI, Ascherio A. Relation between clinical depression risk and physical activity and time spent watching television in older women: a 10year prospective follow-up study. Am J Epidemiol. 2011;174(9):1017-27.

35. Sanchez-Villegas A, Ara I, Guillen-Grima F, Bes-Rastrollo M, VaroCenarruzabeitia JJ, Martinez-Gonzalez MA. Physical activity, sedentary index, and mental disorders in the SUN cohort study. Med Sci Sports Exerc. 2008;40(5):827-34.

36. Kroenke K, Spitzer RL, Williams JB. The Phq-9. J Gen Intern Med. 2001;16(9):606-13.

37. Manea L, Gilbody S, McMillan D. Optimal cut-off score for diagnosing depression with the patient health questionnaire (PHQ-9): a meta-analysis. Can Med Assoc J. 2012;184(3):E191-6.

38. Rosenberg DE, Bull FC, Marshall AL, Sallis JF, Bauman AE. Assessment of sedentary behavior with the international physical activity questionnaire J Phys Act Health. 2008;5:S30-44.

39. Booth ML, Ainsworth BE, Pratt M, Ekelund U, Yngve A, Sallis JF, Oja P. International physical activity questionnaire: 12-country reliability and validity. Med Sci Sports Exerc. 2003;195(9131/03):3508-1381.

40. Haskell WL, Lee I-M, Pate RR, Powell KE, Blair SN, Franklin BA, Macera CA, Heath GW, Thompson PD, Bauman A. Physical activity and public health: updated recommendation for adults from the American College of Sports Medicine and the American Heart Association. Circulation. 2007;116(9):1081-93.

41. Vallance JK, Winkler EA, Gardiner PA, Healy GN, Lynch BM, Owen N. Associations of objectively-assessed physical activity and sedentary time with depression: NHANES (2005-2006). Prev Med. 2011;53(4):284-8.
42. Sugiyama T, Healy GN, Dunstan DW, Salmon J, Owen N. Is television viewing time a marker of a broader pattern of sedentary behavior? Ann Behav Med. 2008;35(2):245-50.

43. Daley A. Exercise and depression: a review of reviews. J Clin Psychol Med Settings. 2008;15(2):140-7.

44. Stathopoulou G, Powers MB, Berry AC, Smits JA, Otto MW. Exercise interventions for mental health: a quantitative and qualitative review. Clin Psychol Sci Pract. 2006;13(2):179-93.

45. Steinberg H, Sykes EA. Introduction to symposium on endorphins and behavioural processes; review of literature on endorphins and exercise. Pharmacol Biochem Behav. 1985;23(5):857-62

46. Bahrke MS, Morgan WP. Anxiety reduction following exercise and meditation. Cogn Ther Res. 1978;2(4):323-33.

47. Taylor AH, Doust J, Webborn N. Randomised controlled trial to examine the effects of a GP exercise referral programme in Hailsham, east Sussex, on modifiable coronary heart disease risk factors. J Epidemiol Community Health. 1998;52(9):595-601.

48. Brosse AL, Sheets ES, Lett HS, Blumenthal JA. Exercise and the treatment of clinical depression in adults. Sports Med. 2002;32(12):741-60.

49. Kraut R, Patterson M, Lundmark V, Kiesler S, Mukophadhyay T, Scherlis W. Internet paradox: a social technology that reduces social involvement and psychological well-being? Am Psychol. 1998;53(9):1017-31.

50. Thomée S, Eklöf M, Gustafsson E, Nilsson R, Hagberg M. Prevalence of perceived stress, symptoms of depression and sleep disturbances in relation to information and communication technology (ICT) use among young adults-an explorative prospective study. Comput Hum Behav. 2007;23(3):1300-21.

51. Morgan C, Cotten SR. The relationship between internet activities and depressive symptoms in a sample of college freshmen. Cyberpsychol Behav. 2003;6(2):133-42.

52. Organisation for Economic Co-operation and Development: OECD Broadband Portal. In: Household and business ICT usage surveys. Edited by OECD; 2016.

53. Korea Internet \& Security Agency. Survey on the mobile internet usage in 2015 (Korean). Edited by KISA, Republic of Korea; 2016.

\section{Submit your next manuscript to BioMed Central and we will help you at every step:}

- We accept pre-submission inquiries

- Our selector tool helps you to find the most relevant journal

- We provide round the clock customer support

- Convenient online submission

- Thorough peer review

- Inclusion in PubMed and all major indexing services

- Maximum visibility for your research

Submit your manuscript at www.biomedcentral.com/submit
C) Biomed Central 